\title{
The Predictive Impact of Contextual Factors on Activity-based Costing Adoption
}

\author{
Robert Rankin \\ Texas A\&M University- Commerce
}

This study investigates the relationship among six contextual factors and activity-based costing (ABC) adoption in the United States to determine what extent they predict ABC adoption. The contextual factors are: (1) intensity of competition, (2) organizational size, (3) cost structure, (4) importance of cost information, (5) strategy, and (6) and industry sector. A survey was sent to 480 large companies or strategic business units (SBU's) (sales greater than $\$ 50$ million). ABC adoption for is $41.75 \%$, which is significantly higher than previous studies for similar countries. Only cost structure is determined to be a significant negative predictor of ABC adoption.

Keywords: activity-based costing, $A B C$, contextual factors, $A B C$ adoption

\section{INTRODUCTION}

When introduced in the late 1980's, activity-based costing (ABC) (Johnson and Kaplan, 1987) was considered the greatest innovation in management accounting (MA) in the $21^{\text {st }}$ century (Grondskis and Sapkauskiene, 2011), receiving considerable attention in academic and practitioner publications. Although empirical evidence exists to support ABC's positive role in improving company performance, productivity, and profitability (Askarany, Yazdifar, and Askary, 2010; Elhamma, 2012; Jankala and Silvola, 2012), on average, global ABC adoption on average has not exceeded $20.00 \%$ worldwide (AlOmiri and Al-Qura, 2012; Askarany et al., 2010; Charaf and Bescos, 2013; Nassar, Al-Khadash, Sangster, and Mah'd, 2013; Schoute, 2011). Researchers determined that ABC is adopted at higher rates in developed countries (Askarany and Yazdifar, 2012) than in undeveloped countries and that the importance of cost information is predictive and positively associated with $\mathrm{ABC}$ adoption (Ahmadzadeh, Etemaldi and Pifeh, 2011; Askarany et al., 2010; Charaf and Bescos, 2013; Schoute, 2011).

In over two decades, researchers found significant variability in $\mathrm{ABC}$ adoption rates ranging from as low as $4.00 \%$ (Drury and Tayles, 2000) to as high as $78.00 \%$ (Baird, Harrison, and Reeve, 2004). Factors identified as contributing to the variability in $\mathrm{ABC}$ adoption rates include: operationalization of $\mathrm{ABC}$ adoption (dichotomous vs. user determined: Al-Omiri and Drury, 2007b; Askarany et al., 2010; Krumwiede, 1998), industry sector (manufacturing vs. service: Ahmadzadeh et al., 2011; Askarany et al., 2010; Schoute, 2011) and the country investigated (developed vs. undeveloped: Askarany and Yazdifar, 2012). Empirical investigation into the impact of contextual factors predictive of $A B C$ adoption including; intensity of competition, product diversity, cost structure, organizational size, and the importance of cost information were unable to determine a consistent relationship with $\mathrm{ABC}$ adoption (Ahmadzadeh et al., 2011; Al-Omiri and Drury, 2007b; Charaf and Bescos, 2013; Nassar et al., 2013; Schoute, 2011). 
The purpose of this study is to investigate the relationship among six contextual factors predictive of $\mathrm{ABC}$ adoption including (1) intensity of competition, (2) organizational size, (3) cost structure, (4) importance of cost information, (5) strategy, and (6) industry sector and advance the knowledge of why $\mathrm{ABC}$ is not more widely-adopted in a developed country.

\section{LITERATURE REVIEW HYPOTHESES}

\section{Activity-based Costing}

When introduced, expectations were high, in the MA community, that most companies would replace extant costing systems with ABC (Cooper, 1988a, 1988b, 1989a, 1989b). Earlier research conducted on $\mathrm{ABC}$ concentrated on the exposition of the how, when and why of $\mathrm{ABC}$ adoption (Anderson, 1995; Argyris and Kaplan, 1994; Booth and Giacobbe, 1999; Estrin, Kantor and Albers, 1994; McGowan and Klammer, 1997). With $\mathrm{ABC}$ adoption averaging around $25.00 \%$ in most studies (Armitage and Nicholson, 1993; Clarke and Mia, 1993), Gosselin (1997) termed the phenomenon the "ABC paradox" stating "if $\mathrm{ABC}$ has demonstrated benefits why are more firms not employing it?" (p. 805). Identification of the $\mathrm{ABC}$ paradox was pivotal in shifting $\mathrm{ABC}$ research from exposition to empirical investigation as to why $\mathrm{ABC}$ is not more widely-adopted.

Research into the variability in ABC adoption rates (Ahmadzadeh et al., 2011; Al-Omiri, 2007a; Askarany et al., 2010; Schoute, 2011), and the relationship among contextual factors and ABC adoption (Ahmadzadeh et al., 2011; Al-Omiri and Drury, 2007b; Charaf and Bescos, 2013; Nassar et al., 2013; Schoute, 2011) yielded inconsistent results as to why ABC is not more widely adopted. In the following section, a discussion about variability in $\mathrm{ABC}$ adoption rates and the contextual factors predictive of $\mathrm{ABC}$ adoption, is followed by the research hypotheses.

\section{Variability in ABC Adoption Rates}

In empirical research, $\mathrm{ABC}$ adoption rates vary widely from $4.00 \%$ to $78.00 \%$ generally averaging from $10.00 \%$ to $30.00 \%$. Multiple factors may have contributed to the variability in ABC adoption rates including confusion over the definition of $\mathrm{ABC}$, the manner researchers' operationalized $\mathrm{ABC}$ adoption, and the country researched. Among MA researchers, the $\mathrm{ABC}$ definition is illusive with some researchers failing to define $\mathrm{ABC}$, and yet with others combining $\mathrm{ABC}$ and activity-based management $(\mathrm{ABM})$ into $\mathrm{ABCM}$ to research $\mathrm{ABC}$. When respondents dichotomously self-specified $\mathrm{ABC}$ adoption as either adopted or not-adopted or $\mathrm{ABC}$ adoption was undefined, the results were lower than when researchers determined $\mathrm{ABC}$ adoption based on respondent-provided measures of $\mathrm{ABC}$ associated activities (Askarany and Yazdifar, 2012; Chenhall and Langfield-Smith, 1998; Gosselin 1997; Krumwiede, 1998). The stage of a country's economic development for the company investigated significantly influenced $\mathrm{ABC}$ adoption rates (Askarany and Yazdifar, 2012). In economically developed countries, companies adopted $\mathrm{ABC}$ at higher rates than companies in less economically developed countries (Ahmadzadeh et al., 2011; Al-Omiri and Al-Qura, 2012; Askarany et al., 2010; Schoute, 2011).

\section{Operationalization of ABC Adoption}

In most studies, ABC adoption was operationalized in two broad ways: (1) dichotomous respondentdetermined (Sleihat, Al-Nimer, and Almahamid, 2012; Stratton, Desroches, Lawson and Hatch, 2009), and (2) researcher determined (Askarany and Yazdifar, 2012; Baird et al., 2007; Chenhall and LangfieldSmith, 1998; Gosselin, 1997; Krumwiede, 1998). Wide variability in ABC adoption rates is an outcome of the varying approaches to operationalize $\mathrm{ABC}$ adoption. $\mathrm{ABC}$ adoption rates, where researchers dichotomously operationalized $\mathrm{ABC}$ adoption (adopted or not-adopted), were lower (Askarany and Yazdifar, 2012; Chenhall and Langfield-Smith, 1998; Sleihat et al., 2012; Stratton et al., 2009) than in studies where researchers operationalized $\mathrm{ABC}$ adoption based on respondent replies, on as many as ten levels of adoption (Askarany and Yazdifar, 2012; Baird et al., 2007; Gosselin, 1997; Krumwiede, 1998).

In one of the first studies of ABC adoption using multiple levels of adoption, Gosselin (1997) used innovation literature to investigate the effect of strategy and organizational structure for SBU's of 
Canadian manufacturers. Seventy-seven companies, or nearly $48.00 \%$ of the companies adopted ABC. Strategy and organizational structure were determined to positively influence ABC adoption. Centralized companies with strategies reliant on innovation were more likely to adopt $\mathrm{ABC}$ than were decentralized companies not reliant on innovation.

In a study of $\mathrm{ABC}$ adoption and implementation for United States manufacturing companies a model identifying 10 levels of $\mathrm{ABC}$ implementation was developed. The first five levels considered adoption from $\mathrm{ABC}$ not being considered to analysis and the last five levels considered implementation from getting acceptance to integration (Krumwiede, 1998). Slightly more than $35.00 \%$ of respondents adopted or implemented $\mathrm{ABC}$.

A distinction was made between $\mathrm{ABC}$ users and adopters, in a study of Dutch manufacturing companies, to investigate the influence of product diversity and the usage of alternative manufacturing technologies on ABC adoption (Schoute, 2011). Five levels were used to describe a company's current situation, with respect to $\mathrm{ABC}$ adoption, currently using $\mathrm{ABC}$, currently implementing $\mathrm{ABC}$, currently considering $\mathrm{ABC}$ adoption, no consideration for $\mathrm{ABC}$ adoption, and rejected $\mathrm{ABC}$. Respondents currently using or implementing $\mathrm{ABC}$ were considered $\mathrm{ABC}$ adopters. $\mathrm{ABC}$ adoption and use rates were surprisingly low, with $17.30 \%$ of companies using $\mathrm{ABC}$ and $10.50 \%$ implementing $\mathrm{ABC}$.

To investigate the impact of methodological differences on mixed $\mathrm{ABC}$ adoption rates, Askarany and Yazdifar (2012) operationalized stages and levels of ABC adoption in a study of 584 accountants from the Chartered Institute of Management Accountants (CIMA) representing companies from Australia, New Zealand, and the United Kingdom. Stages were measured using a Likert-type scale ranging from: $A B C$ discussions have not taken place, to $A B C$ has been implemented and accepted (Abdel-Kader and Luther, 2006; Innes, Mitchell and Sinclair, 2000) and stages of adoption and implementation (Gosselin, 1997). Reported levels of $\mathrm{ABC}$ adoption were nearly double for each country averaging $40.00 \%$ compared to $20.00 \%$ when measured with stages.

\section{Country Investigated}

Economically developed countries (Al-Omiri and Drury, 2007b; Askarany et al., 2010; Abdel-Kader and Luther, 2006) adopt $\mathrm{ABC}$ at higher rates than economically developing countries (Ahmadzadeh et al., 2011; Charaf and Bescos, 2013). ABC adoption rates, when measured in multiple levels, are nearly double, than those measured in dichotomous stages (Askarany and Yazdifar, 2012). Although service companies are expected to adopt $\mathrm{ABC}$ at higher rates than manufacturing companies, research has been unable to identify a consistent association between $\mathrm{ABC}$ adoption and industry sector (Askarany et al., 2010; Ahmadzadeh et al., 2011; Schoute, 2011). Research on the relationship among contextual factors predictive of $\mathrm{ABC}$ adoption, such as intensity of competition, product diversity, cost structure, company size, the importance of cost information, and strategy yielded, inconsistent and sometimes contradictory findings (Ahmadzadeh et al., 2011; Askarany et al., 2010; Charaf and Bescos, 2013; Schoute, 2011). Only the importance of cost information was found to consistently be positively-associated with ABC adoption. Strategic decision-making and operational evaluations made based on inaccurate cost object costs can adversely affect a company's ability to compete in an intensely-competitive global economy.

A significant association between reported adoption rates and the country investigated exists (Askarany and Yazdifar, 2012). A country's level of economic development influences variability in reported $\mathrm{ABC}$ adoption rates, making cross-country comparisons difficult. $\mathrm{ABC}$ adoption rates are higher in economically developed countries than in less economically developed countries (Ahmadzadeh et al., 2011; Anh et al., 2011; Charaf and Bescos, 2013). Country specific environmental factors, such as economic stability and education systems influence the rate of $\mathrm{ABC}$ adoption.

$\mathrm{ABC}$ adoption in economically developed countries, such as Australia, New Zealand, the United Kingdom, Canada, and the United States generally exceed $20.00 \%$ whereas less economically developed countries such as Iran, Jordan, and Romania ABC adoption rates are generally less than 10\% (Ahmadzadeh et al., 2011;Cardos, Pete, and Cardos, 2012; Nassar et al., 2013). In economically developed countries, the contingency theory of organizations which suggests the selection of product costing system (PCS) is dependent on organizational contingencies has been used to investigate $\mathrm{ABC}$ 
adoption (Abdel-Kader and Luther, 2006; Al-Omiri and Drury, 2007b). In economically less-developed countries, the diffusion of innovation theory which simply states a fundamental factor in determining whether a specific innovation is favorably received and ultimately adopted is the extent to which a perspective adopter views compatibility of the innovation as being consistent with previous beliefs, practices and experience to investigate $\mathrm{ABC}$ adoption (Anh et al., 2011).

A review of research into $\mathrm{ABC}$ adoption, over time, in economically developed countries provides insight into trends of $\mathrm{ABC}$ adoption. Research into $\mathrm{ABC}$ adoption rates for the largest United States companies, over time, exhibited the same phenomenon with $\mathrm{ABC}$ adoption peaking at about $20.00 \%$ (Ernst and Young, 2003). In more recent research, worldwide ABC adoption rates averaged 18.60\% (Stratton et al., 2009). ABC adoption rates varied between $6.30 \%$ and $43.20 \%$ from undeveloped to developed economies (Askarany and Yazdifar, 2012; Cardos, et al., 2012).

\section{Contextual Factors}

Researchers investigated the relationship among contextual factors predictive of $\mathrm{ABC}$ adoption. When $\mathrm{ABC}$ was introduced, intensity of competition, customers' demands for increased product diversity, and shifts in cost structures were identified as foundational contextual factors driving the necessity for improved cost accuracy (Cooper, 1988a, 1988b, 1989a, 1989b). Empirical investigation into the impact of the foundational contextual factors (Ahmadzadeh et al., 2011; Al-Omiri and Drury, 2007b; Charaf and Bescos, 2013; Nassar et al., 2013) as well as contemporary contextual factors of size, the importance of cost information, and strategy have been unable to determine a consistent positive relationship among their existence and ABC adoption (Ahmadzadeh et al., 2011; Al-Omiri and Drury,2007b; Charaf and Bescos, 2013; Nassar et al., 2013; Schoute, 2011).

\section{Intensity of Competition}

Facing intense competition, companies tend to require more accurate costs for decision-making; thus making competition one of the contributing factors for them to consider when considering $\mathrm{ABC}$ adoption (Cooper, 1988b). Competitors are much more likely to exploit decision-making mistakes relying on inaccurate costs, when competition is intense. Thus in a competitive environment, companies require accurate costs to maintain competitive advantage, make optimal strategic decisions and evaluate operations.

In MA literature, the influence of intensity of competition on $\mathrm{ABC}$ adoption was found to have both positive (Al-Omiri and Drury, 2007b; Nassar et al., 2013) and negative (Pavlatos and Paggios, 2009; Brierley, 2008) impacts. In studies of service and manufacturing companies from the United Kingdom (Al-Omiri and Drury,2007b) and Jordanian manufacturing, electricity producing and mining companies (Nassar et al., 2013), ABC adoption was found to be positively associated with intensity of competition. While in studies of manufacturing companies from the United Kingdom (Brierley, 2008) as well as in companies from the Greek hospitality industry (Pavlatos and Paggios, 2009), a negative relationship between $\mathrm{ABC}$ adoption and intensity of competition was discovered.

\section{Cost Structure}

A fundamental premise of $\mathrm{ABC}$ was shifting from direct labor (direct costs) intensive to capital intensive cost structures (indirect costs) which reduced the accuracy of cost object costs accuracy generated from traditional costing (TC) systems (Kaplan and Cooper, 1998). When indirect costs represent a higher proportion of total costs, the greater a company's need for $\mathrm{ABC}$. Conversely, when indirect costs are low as a proportion of total costs, TC or variable costing may be adequate (Al-Omiri and Drury, 2007b).

In studies of the impact of the relationship between cost structure and $\mathrm{ABC}$ adoption, results are mixed. In two separate studies of UK companies, manufacturing operating units (Brierley, 2008) and service and manufacturing companies (Al-Omiri and Drury, 2007b), cost structures were found to have a negative impact on $\mathrm{ABC}$ adoption. In a study of companies listed on the Iranian stock exchange, a positive relationship existed between cost structure and ABC adoption (Ahmadzadeh et al., 2011). For 
Jordanian companies, cost structure was found to be positively associated with ABC adoption (Charaf and Bescos, 2013), whereas, in another study of Jordanian manufacturing companies Rhaba'h (2013) determined a negative relationship between $\mathrm{ABC}$ adoption and cost structure.

\section{Product Diversity}

Product diversity, generally considered one of the primary reasons for distortion in product costs (Cooper, 1988b), is the condition whereby the product variation places varying demands on company's resources or activities (Schoute, 2011). Product diversity includes support, process, and volume diversity (Cooper, 1988b; Estrin, et al., 1994). Support diversity refers to support given by different support departments to a product. Process diversity is a function of the differences in consumption of activities focused on product design, manufacture, and distribution. Differences in batch size of production are key determinants in volume diversity affecting the assignment of batch level costs to products. When products consume a disproportionate amount of indirect costs, the potential for product diversity, exists leading to distorted product costs (Al-Omiri and Drury, 2007b).

In a study of the impact of manufacturing and non-manufacturing companies from the United Kingdom, volume and support diversity were determined not to predict variables of sophisticated PCS (ABC) (Al-Omiri and Drury, 2007b). Similarly, in an investigation of Iranian service and manufacturing companies neither volume or support diversity was discovered to influence ABC adoption (Ahmadzadeh et al., 2011). Schoute (2011) measuring product diversity using the number of products and the degree of variation between products, determined there was a positive relationship between $A B C$ adoption and product diversity for medium-sized manufacturing companies from the Netherlands. For Moroccan manufacturing and service companies, product diversity measured with the number of lines was found not to influence ABC adoption (Charaf and Bescos, 2013).

\section{Size}

The relationship between company size and $\mathrm{ABC}$ adoption is one of the most controversial contextual factors (Askarany et al., 2010). Smaller companies closer to the market with less bureaucracy and an entrepreneurial spirit were determined to be more receptive to adopting ABC (Shields and Young, 1994). Conversely, larger companies with greater access to human, capital, and technological resources are more likely to adopt ABC than smaller companies (Brown, Booth, and Giacobbe, 2004; Innes and Mitchell, 1995). The number of employees and sales are used to measure the relationship between size and ABC adoption.

Multiple studies investigating the influence of size, used the number of employees and reported inconsistent results, on its impact on $\mathrm{ABC}$ adoption. In a study of Australian public sector organizations including government entities, hospitals and universities, size was not a key determinant of activity management practices (Baird et al., 2007). For Jordanian manufacturing companies, the number of employees was determined to not be positively associated with ABC adoption (Rhaba'h, 2013). Elhamma (2012) determined a positive relationship between size and ABC adoption in a study of a mixed sample of small, medium, and large Moroccan service and manufacturing companies. An investigation of $\mathrm{ABC}$ adoption rates in New Zealand revealed that larger companies, in terms of the number of employees, adopted $\mathrm{ABC}$ at higher rates (Askarany et al., 2010).

Sales is another metric used to measure the impact of size on $\mathrm{ABC}$ adoption. In recent studies, the influence of size in terms of sales on $\mathrm{ABC}$ had mixed results. In a study of publically-traded Iranian companies, size was determined to have no significant influence on the $\mathrm{ABC}$ adoption (Ahmadzadeh et al., 2011). ABC adoption was found to be positively-associated with company size in a study of large UK manufacturing and service companies, (Al-Omiri and Drury, 2007b). Likewise, ABC adoption rates were positively associated with size, in terms of sales, in a study of operating units in UK manufacturing companies (Brierley, 2008). A statistically significant association was determined between the stages of $\mathrm{ABC}$ adoption and size. No association was determined between the levels of $\mathrm{ABC}$ adoption and size for service and manufacturing companies from New Zealand (Askarany et al., 2010). 


\section{Importance of Cost Information}

Providing relevant cost information for strategic decision-making and operational evaluation is a major role of PCS. Cost object costs are used to evaluate cost object and customer profitability; thus providing an insight into the needed operational modifications in terms of price changes or production or service delivery processes. If PCS provides distorted or inaccurate cost object costs, operational decisionmaking intended to increase profitability may decrease profitability. At high levels of profit margins, the need for accurate cost object costs diminishes whereas at low levels of profit margins, the need for accurate cost object costs increases.

In all studies of $\mathrm{ABC}$ adoption, the importance of cost information was consistently determined to be positively-associated with $\mathrm{ABC}$ adoption. For Iranian service and manufacturing companies listed on the Tehran stock exchange, the importance of cost information was found to have a positive impact on $\mathrm{ABC}$ adoption (Ahmadzadeh et al., 2011). In an investigation of manufacturing, financial services and retail companies from the United Kingdom, $\mathrm{ABC}$ adoption was found to be positively-associated with the importance of cost information (Al-Omiri and Drury, 2007b). Using three stages of adoption to investigate the impact of the importance of cost information for Moroccan service and manufacturing companies, Charaf and Bescos (2013) determined a positive association.

\section{Strategy}

Strategy, unlike other contingencies, is not a component of context, but rather a mechanism by which managers exert influence on elements of the external environment, organizational technologies, organizational structure, and control culture (Chenhall, 2006). Multiple generic strategy taxonomies have been developed including prospector-analyzer-defenders (Miles and Snow, 1978), and product differentiation-cost leadership. Prospector, build, and product differentiation strategies are characterized by a lack of standardized procedures, decentralization, results-orientation, and attention focused on curbing innovation suggesting a predisposition to adopting innovative MAPs (Chenhall, 2006). The type of strategy a company employs can greatly influence the effectiveness and efficiency of MAPs, such as $\mathrm{ABC}$ (Chenhall, 2006).

In a study of SBU's of Canadian large manufacturing companies likely to adopt $\mathrm{ABC}$ based on company characteristics, the relationship between strategy and multiple stages of $\mathrm{ABC}$ adoption including activity analysis (AA), activity cost analysis (ACA), and ABC collectively activity management (AM), Gosselin (1997) determined a positive and significant correlation between AM and prospector strategy suggesting prospectors tend to adopt $\mathrm{AA}, \mathrm{ACA}$ and $\mathrm{ABC}$ at higher frequencies than analyzers and defenders. In a study of a cross-section of Moroccan small, medium, and large service and manufacturing companies where respondents rated seven strategy items between defenders and prospectors (Mouline, 2000) business strategy had no significant relationship with ABC adoption (Elhamma and Fei, 2013).

\section{Dependent Variable and Hypotheses}

Previous studies yielded mixed results concerning the relationship among $\mathrm{ABC}$ adoption and contextual factors. The multiplicity of terms used to operationalize $\mathrm{ABC}$ adoption yielded significant variability in $\mathrm{ABC}$ adoption rates, industry sector (service vs. manufacturing) and a country's stage in economic development (Askarany and Yazdifar, 2012; Baird et al., 2007; Chenhall and Langfield-Smith, 1998; Gosselin, 1997; Krumwiede, 1998). ABC research suggests respondent-determined ABC adoption using dichotomous operationalization of $\mathrm{ABC}$ (not-adopted or adopted), yielded significant variability in ABC adoption rates (Gosselin, 1997; Krumwiede, 1998; Askarany and Yazdifar, 2012).

Research suggests industry sector: service or manufacturing (Ahmadzadeh et al., 2011; Askarany et al., 2010; Schoute, 2011) impacts ABC adoption rates. For this study, service and manufacturing companies are included to determine the impact of industry sector on $\mathrm{ABC}$ adoption rates. Respondents self-classified industry sector as service (accommodation and food service, health care, information, transportation and warehousing, and utilities) or manufacturing (manufacturing, and mining, quarrying and gas extraction). 
Researchers found higher $\mathrm{ABC}$ adoption rates for economically developed countries than for less economically developed countries (Ahmadzadeh et al., 2011; Anh et al., 2011; Charaf and Bescos, 2013) impacted by country specific environmental factors such as economic stability and education systems. In economically developed countries, ABC adoption generally exceeded $20.00 \%$ compared to less economically developed countries at less than 10.00\% (Ahmadzadeh et al., 2011; Cardos, Pete, and Cardos, 2012; Nassar et al., 2013). For this study, companies or SBU's from the United States, a developed country were surveyed.

Multiple studies investigated contextual factors predictive of $\mathrm{ABC}$ adoption with only the importance of cost information found to be positively-associated with ABC adoption across all studies (Ahmadzadeh et al., 2011; Al-Omiri and Drury, 2007b; Charaf and Bescos, 2013; Nassar et al., 2013; Schoute, 2011). In this study, a mix of the foundational contextual factors (cost structure, product diversity and intensity of competition) as well as contemporary contextual factors (organizational size, importance of cost information, strategy and industry sector) are investigated. The following hypotheses are explored in the present study:

$\boldsymbol{H}_{1}$ : Intensity of competition is a significant predictor of $A B C$ adoption.

$\boldsymbol{H}_{2}:$ Organizational size is a significant predictor of $A B C$ adoption.

$\boldsymbol{H}_{3}:$ Cost structure is a significant predictor of $A B C$ adoption.

$\boldsymbol{H}_{4}:$ The importance of cost information is a significant predictor of ABC adoption.

$\boldsymbol{H}_{5}:$ Organizational strategy is a significant predictor of $A B C$ adoption.

$\boldsymbol{H}_{6}:$ Industry sector is a significant predictor of ABC adoption.

Using industry sector (service/manufacturing) as a control variable, the hypotheses are designed to elucidate the relationship among contextual factors and $\mathrm{ABC}$ adoption.

\section{RESEARCH DESIGN}

\section{Sample Selection}

A simple random sampling of finance professionals from large service or manufacturing companies or SBU's, with sales above $\$ 50$ million, from the United States with knowledge of their cost management practices was surveyed. The sample is isolated to specific service (accommodation and food service, health care, information, transportation and warehousing, and utilities) and manufacturing (manufacturing, and mining, quarrying and gas extraction) companies or SBUs who would accrue the greatest benefit from adopting $\mathrm{ABC}$ based on industry characteristics.

\section{ABC Adoption (Dependent Variable)}

$\mathrm{ABC}$ adoption is viewed as a whole practice with multiple different stages on a continuum anchored by statements such as decided not to use $A B C$ and decided to use $A B C$ (Al-Omiri and Drury, 2007a; Anderson, 1995; Askarany and Yazdifar, 2012). ABC research suggests respondent determined ABC adoption using dichotomous operationalization of $\mathrm{ABC}$ (not-adopted or adopted) yielded significant variability in $\mathrm{ABC}$ adoption rates (Gosselin, 1997; Krumwiede, 1998; Askarany and Yazdifar, 2012). To minimize variability in respondent determined $\mathrm{ABC}$ adoption, $\mathrm{ABC}$ adoption was measured using a 7 point Likert-type scale (Abdel-Kader and Luther, 2008; Askarany and Yazdifar, 2012) as follows: discussions have not taken place regarding the introduction of ABC adoption; a decision has been taken not to introduce $A B C$; some consideration is being given to the introduction of $A B C$ introduction in the future; $A B C$ has been introduced on a trial basis; $A B C$ has been implemented and accepted; and $A B C$ 
was implemented and later rejected. $\mathrm{ABC}$ adoption was researcher-determined for respondents selecting: $A B C$ has been introduced on a trial basis; $A B C$ has been implemented and accepted; and ABC was implemented and later rejected were considered $\mathrm{ABC}$ adopters with an assigned value of one, and with respondents selecting: discussions have not taken place regarding the introduction of ABC adoption; a decision has been taken not to introduce $A B C$; some consideration is being given to the introduction of $A B C$ introduction in the future were considered $\mathrm{ABC}$ non-adopters with an assigned value of zero.

\section{Contextual Factors (Independent Variables)}

The purpose of this study is to investigate the relationship among independent variables (contextual factors: intensity of competition, organizational size, cost structure, the importance of cost information, strategy, and industry sector) and $\mathrm{ABC}$ adoption for service and manufacturing companies from the United States to determine to what extent, if any, they are predictive of $\mathrm{ABC}$ adoption. Presented in this section is a discussion of the measurement of the independent variables.

\section{Intensity of Competition}

The intensity of competition was based on the degree to which competitors influence a company's decision-making. To measure this variable, respondents indicated the intensity of competition for their company or division on price, product, and market on a 5-point Likert-type scale as follows: not at all; to a little extent; to some extent; to a considerable extent; to a very great extent (Khandwalla, 1972; Schoute, 2011). A composite scale is constructed averaging their responses.

\section{Company Size}

The most frequently used proxy to measure size is the number of employees (Gosselin, 1997). Multiple potential measures of size were considered for this study, including annual sales, total assets, total revenue, and number of employees. Changes in the other factors outside of the number of employees occur more frequently making them less reliable to measure size (Askarany et al., 2010). Thus, the number of employees is used to measure size in this study. The number of employees is measured on six levels as follows: less than 100; 100-200; 201-500; 501-1,000; 1,001-10,000; and over 10,000. To scale the data for analysis, respondents are classified as small (0-500 employees), medium $(501-1,000)$ and large (greater than 1,000 employees).

\section{Importance of Cost Information}

To measure the importance of cost information respondents rated the following nine components: decisions on selling price, make or buy, cost reduction, product mix, output level, product design, evaluation of new product processes, product discontinuation, and operational evaluation (Al-Omiri and Drury, 2007b) on a 6-point Likert-type scale as follows: very important; important; neither important or unimportant; unimportant; very unimportant; or do not make this type of decision.

\section{Cost Structure}

Respondents provided a breakdown of costs to provide service or manufacturing costs divided into three categories: direct materials, direct labor and indirect costs that summed to $100 \%$. From the captured data, the indirect cost percentage is used to determine the amount of indirect cost represents as a percentage of total costs (Al-Omiri and Drury, 2007b).

\section{Strategy}

The strategy variable is based on the typology of defender-prospector-analyzer-reactor (Miles and Snow, 1978). Respondents' self-specified strategy based on one of four generic strategies consistent with Snow and Hrebiniak's (1980) instrument as follows: type 1 (defender); type 2 (prospector); type 3 (analyzer); type 4 (reactor). For the survey instrument, the descriptors in parenthesis are omitted. Companies or SBUs following defender or analyzer strategies dependent on accurate cost information for 
sustainability is assigned a value of one whereas those with strategies (prospector and reactor) not dependent on accurate costs are assigned a value of zero.

\section{ANALYSIS}

The target population for this study is limited to specific industries, most likely to adopt ABC from the United States. A total of 408 surveys were distributed with 357 total responses and 103 valid responses representing a $28.85 \%$ response rate with $66.00 \%$ of respondents holding senior finance positions of executive officer, chief financial officer, vice president or controller with than half $(58.30 \%)$ having greater than five years of experience as qualified accountants (Table 1).

TABLE 1

DISTRIBUTION OF RESPONDENTS BY TITLE AND EXPERIENCE

\begin{tabular}{lcccccc}
\hline \multicolumn{1}{c}{ Title } & $\mathrm{c}$ Years of Experience as a Qualified Accountant \\
& $\mathrm{N}$ & $<$ 2 years & $2-5$ years & $5-10$ years & $10-15$ & >15 years \\
& & & & & years & \\
\hline Vice President & 40 & 3 & 11 & 13 & 8 & 5 \\
CFO* & 13 & 6 & 2 & 2 & 2 & 1 \\
Accountant & 9 & 0 & 1 & 1 & 2 & 5 \\
Analyst & 9 & 3 & 2 & 2 & 1 & 1 \\
Controller & 9 & 0 & 0 & 2 & 1 & 6 \\
Other & 7 & 4 & 2 & 0 & 0 & 1 \\
Director/Manager & 6 & 2 & 0 & 1 & 2 & 1 \\
Executive Officer & 6 & 0 & 1 & 3 & 0 & 2 \\
Supervisor & 4 & 0 & 2 & 1 & 1 & 0 \\
$\quad$ Total & 103 & 18 & 21 & 25 & 17 & 22 \\
\hline
\end{tabular}

Note. ${ }^{*} \mathrm{CFO}=$ Chief Financial Officer

The frequency distribution of the sample was evenly distributed between service $(49.50 \%)$ and manufacturing (50.50\%). A distribution of respondents is presented (Table 2).

TABLE 2

INDUSTRY GROUP

\begin{tabular}{|c|c|c|}
\hline Industry Group & $\mathrm{n}$ & Total \\
\hline Accommodation, Food Service & 23 & \\
\hline Transportation and Warehousing & 19 & \\
\hline Health Care & 9 & \\
\hline Service Total & & 51 \\
\hline Manufacturing & 37 & \\
\hline Utilities & 9 & \\
\hline Mining, Quarrying, Gas Extraction & 6 & \\
\hline Overall Total & & $\begin{array}{c}52 \\
103\end{array}$ \\
\hline
\end{tabular}

\section{ABC Adoption}

In this study, combined $\mathrm{ABC}$ adoption is $41.75 \%$ which is considerably higher than $\mathrm{ABC}$ adoption in other developed countries (Ahmadzadeh et al., 2011; Anh et al., 2011; Charaf and Bescos, 2013). The $\mathrm{ABC}$ adoption gap between service (35.29\%) and manufacturing $(48.08 \%)$ is exactly as expected as the 
potential benefits of $\mathrm{ABC}$ adoption for manufacturing companies generally exceeds those of service companies. A potential contributing factor to higher $\mathrm{ABC}$ adoption in the present study is the inclusion of companies or SBU's with sales above $\$ 50$ million. While operationalization of ABC adoption, into dichotomous stages, in prior studies (Askarany and Yazdifar, 2012) yielded lower ABC adoption rates; lower $\mathrm{ABC}$ adoption rates were not found in this study.

TABLE 3

DISTRIBUTION OF RESPONDENTS AND ADOPTION BY INDUSTRY SECTOR

\begin{tabular}{lcccc}
\hline Industry Sector & $\mathrm{n}$ & Adopter & Non-Adopter & Percent Adopter \\
\hline Manufacturing & 52 & 25 & 27 & $48.08 \%$ \\
Service & 51 & 18 & 33 & $35.29 \%$ \\
All Companies & 103 & 43 & 60 & $41.75 \%$ \\
\hline
\end{tabular}

\section{Logistic Regression}

The results of the logistic regression are presented in Table 4. Organizational size, the importance of cost information and strategy are positively correlated with $\mathrm{ABC}$ adoption. As organizations increase in size (employees), the data suggests they are more likely to adopt ABC. The importance of cost information and strategy variables share a weak link. Companies pursuing strategies (defender or analyzer) dependent on accurate cost information likely highly rated the importance of cost information. Cost structure, the intensity of competition and industry sector were found to be negatively-associated with $\mathrm{ABC}$ adoption. These findings are surprising considering that cost structure is one of the foundational factors cited for the need for improved cost object accuracy. Similarly, the negative $\beta$ coefficient for industry sector indicates that service companies are more likely to adopt $\mathrm{ABC}$ than manufacturing companies.

TABLE 4

\section{RESULTS OF LOGISTIC REGRESSION ANALYSIS}

\begin{tabular}{lcccc}
\hline & $\beta$ coefficient & SE & Wald statistics & Sig. \\
\hline Organizational Size & 0.700 & 0.448 & 2.448 & 0.118 \\
Cost Structure & -0.308 & 0.174 & 3.125 & 0.077 \\
Intensity of Competition & -0.354 & 0.284 & 1.555 & 0.212 \\
Importance of Cost Information & 0.109 & 0.245 & 0.198 & 0.656 \\
Strategy & 0.129 & 0.453 & 0.080 & 0.777 \\
Industry Sector & -0.627 & 0.426 & 2.161 & 0.142 \\
Constant & -0.373 & 1.768 & 0.045 & 0.833 \\
\hline
\end{tabular}

Note. $\mathrm{SE}=$ Standard Error

While the intensity of competition is not found to be a significant predictor of $\mathrm{ABC}$ adoption, the $\beta$ coefficient (-0.354) suggests ABC adoption is negatively-associated with the construct. The findings are consistent with studies of service and manufacturing companies in the United Kingdom (Al-Omiri and Drury,2007b) and Jordanian manufacturing, electricity producing and mining companies (Nassar et al., 2013). Conversely, intensity of competition was determined to be positively associated with ABC adoption for manufacturing companies from the United Kingdom (Brierley, 2008) and the Greek hospitality industry (Pavlatos and Paggios, 2009). 
TABLE 5

MEANS OF INDEPENDENT VARIABLES

\begin{tabular}{lccc}
\hline & $\mathrm{n}$ & COMP & IMPC \\
\hline All & 103 & 3.77 & 4.51 \\
Adopter & 43 & 3.71 & 4.54 \\
Non-adopter & 60 & 3.82 & 4.48 \\
\hline
\end{tabular}

Although not significant findings from the present study for the importance of cost information are consistent with other studies with a $\beta$ coefficient (0.109) indicating the construct is positively associated with $\mathrm{ABC}$ adoption. In all studies of $\mathrm{ABC}$ adoption, the importance of cost information was consistently determined to be positively associated with $\mathrm{ABC}$ adoption. For Iranian service and manufacturing companies listed on the Tehran stock exchange, the importance of cost information was found to have a positive impact on ABC adoption (Ahmadzadeh et al., 2011). In an investigation of manufacturing, financial services and retail companies from the United Kingdom, $\mathrm{ABC}$ adoption was found to be positively-associated with the importance of cost information (Al-Omiri and Drury, 2007b). Using three stages of adoption to investigate the impact of the importance of cost information for Moroccan service and manufacturing companies, Charaf and Bescos (2013) determined a positive association.

TABLE 6

DISTRIBUTION OF SAMPLE INDEPENDENT VARIABLE COST

\begin{tabular}{|c|c|c|c|c|c|c|c|}
\hline & $\mathrm{n}$ & $<10 \%$ & 11 to $20 \%$ & $\begin{array}{l}21 \text { to } \\
30 \%\end{array}$ & $\begin{array}{l}31 \text { to } \\
40 \%\end{array}$ & $\begin{array}{l}41 \text { to } 50 \\
\text { percent }\end{array}$ & $>50 \%$ \\
\hline All & 103 & & & & 1 & 33 & 69 \\
\hline Adopter & 43 & & & & 0 & 11 & 32 \\
\hline Non-adopter & 60 & & & & 1 & 22 & 37 \\
\hline
\end{tabular}

Surprisingly, cost structure as one of the foundational contextual factors originally cited as a fundamental reason for the introduction of $\mathrm{ABC}$ adoption was not found to be a significant predictor of $\mathrm{ABC}$ adoption. Moreover, cost structure is negatively-associated $(\beta=-0.308)$ with $\mathrm{ABC}$ adoption. The findings from this study are consistently inconsistent prior investigations. In studies of the impact of the relationship between cost structure and $\mathrm{ABC}$ adoption, results are mixed. In two separate studies of UK companies, manufacturing operating units (Brierley, 2008) and service and manufacturing companies (AlOmiri and Drury, 2007b), cost structures were found to have a negative impact on ABC adoption. In a study of companies listed on the Iranian stock exchange, a positive relationship existed among cost structure and ABC adoption (Ahmadzadeh et al., 2011). For Jordanian companies, cost structure was found to be positively associated with $\mathrm{ABC}$ adoption (Charaf and Bescos, 2013) whereas in another study of Jordanian manufacturing companies, Rhaba'h (2013) determined a negative relationship between ABC adoption and cost structure.

Nearly all respondents were heavily dependent on overhead costs with only one company reporting overhead costs less than $41.00 \%$. As overhead costs increased, ABC adoption increased. Thirty three percent of respondents with overhead costs between $41.00 \%$ and $50.00 \%$ adopted compared to $46.00 \%$ of respondents with overheads costs greater than $50.00 \%$ adopting $\mathrm{ABC}$. This finding is consistent with the need for a more accurate costing system as overhead costs increase. 
TABLE 7

DISTRIBUTION OF SAMPLE INDEPENDENT VARIABLE SIZE

\begin{tabular}{lcccc}
\hline & $\mathrm{n}$ & Less than $500^{*}$ & 501 to 1,000 & Greater than 1,000 \\
\hline All & 103 & 1 & 33 & 69 \\
Adopter & 43 & 0 & 11 & 32 \\
Non-adopter & 60 & 1 & 22 & 37 \\
\hline
\end{tabular}

Note. *Employees

Forty six percent of companies with greater than 1,000 employees adopted $\mathrm{ABC}$ while only $32.00 \%$ companies with less than 1,000 employees adopted ABC. This suggests, as human and financial capital increase companies may be more apt to adopt ABC. Even though size measured in terms of employees was not considered a significant predictor of $\mathrm{ABC}$ adoption $(\beta=0.700)$, size is positively-associated with $\mathrm{ABC}$ adoption the larger the company. This finding is inconsistent with other studies. In prior studies, size was measured in terms of employees and sales. Using employees to measure size in a study of Australian public sector organizations including government entities, hospitals and universities, size was not a key determinant of activity management practices inclusive of ABC (Baird et al., 2007). For Jordanian manufacturing companies, the number of employees was determined to not be positively associated with the ABC adoption (Rhaba'h, 2013). Elhamma (2012) in a study of a mixed sample of small, medium, and large Moroccan service and manufacturing companies found a positive relationship among size and the adoption of $\mathrm{ABC}$. An investigation of $\mathrm{ABC}$ adoption rates in New Zealand revealed larger companies in terms of the number of employees adopted $\mathrm{ABC}$ at higher rates (Askarany et al., 2010).

Sales is another metric used to measure the impact of size on $\mathrm{ABC}$ adoption. In recent studies, the influence of size, in terms of sales, on $\mathrm{ABC}$ had mixed results. In a study of publically-traded Iranian companies, size was determined to have no significant influence on the $\mathrm{ABC}$ adoption (Ahmadzadeh et al., 2011). ABC adoption was found to be positively associated with company size in a study of large UK manufacturing and service companies, (Al-Omiri and Drury, 2007b). Likewise, ABC adoption rates were positively-associated with size in terms of sales in a study of operating units in UK manufacturing companies (Brierley, 2008). A statistically-significant association was determined between the stages of $\mathrm{ABC}$ adoption and size. No association was determined between the levels of $\mathrm{ABC}$ adoption and size for service and manufacturing companies from New Zealand (Askarany et al., 2010).

TABLE 8 DISTRIBUTION OF SAMPLE INDEPENDENT VARIABLE STRATEGY

\begin{tabular}{lccccc}
\hline & $\mathrm{n}$ & Prospector & Analyzer & Defender & Reactor \\
\hline All & 103 & 35 & 32 & 28 & 8 \\
Adopter & 43 & 15 & 12 & 13 & 3 \\
Non-adopter & 60 & 20 & 20 & 15 & 5 \\
Adoption & & $42.85 \%$ & $37.50 \%$ & $46.40 \%$ & $37.50 \%$ \\
\hline
\end{tabular}

Thirty seven percent of analyzers and $37.00 \%$ of reactors adopted ABC. Not surprisingly $46.40 \%$ of defenders, who are dependent on accurate cost information to implement company strategy, adopted $\mathrm{ABC}$. In the present study, strategy is determined not to be significant $(\beta=0.129)$. With a dichotomous grouping of strategy between accurate cost dependent strategies (prospector/reactor) and less accurate cost dependent strategies (defender/analyzer), the $\beta$ coefficient suggests prospector/reactor strategies are positively-associated with $\mathrm{ABC}$ adoption. Findings from this study are consistent with a similar study of Canadian manufacturing and service companies (Gosselin, 1997), and inconsistent with a study of Moroccan small, medium and large service and manufacturing companies (Mouline, 2000) where business strategy had no significant relationship with ABC adoption (Elhamma and Fei, 2013). 


\section{DISCUSSION AND CONCLUSIONS}

The purpose of this paper is to study to improve the understanding of why $\mathrm{ABC}$ is not more widely adopted. Based on a literature review, the relationship among six contextual factors included: (1) intensity of competition, (2) cost structure, (3) importance of cost information, (4) organizational size, (5) strategy and (6) industry sector. Consistent with other studies, six hypotheses were offered. This paper addresses why more companies have not adopted $\mathrm{ABC}$. The context is large companies or SBU's from the United States who would most likely benefit from $A B C$ adoption including the following industries: accommodation and food service, health care, manufacturing, and mining, quarrying and gas extraction information, transportation and warehousing, and utilities. A total of 408 surveys were distributed to senior finance professionals with knowledge of their company's cost management practices. There 357 total responses with 103 valid responses representing a $28.85 \%$ response rate. The composition of the sample is very similar to all companies from the United States, but it does not suggest the sample is representative of all United States companies or those from other developed countries.

The combined (service \& manufacturing) ABC adoption rate is $41.75 \%$ for this study, with manufacturing companies (48.08\%) and service (35.29\%), suggesting United States companies adopt $\mathrm{ABC}$ at higher rates than other countries. Correspondingly, the expectation is that companies from developed countries adopt $\mathrm{ABC}$ at higher rates than developing or underdeveloped countries. Regarding the relationship among the six contextual factors tested and $\mathrm{ABC}$ adoption, cost structure is the contextual factor that is significantly $(\beta=-0.308)$ negatively-associated with $\mathrm{ABC}$ adoption; thus suggesting that as indirect costs increase companies are less likely to adopt ABC.

A closer analysis of the six variables indicates that organizational size, the importance of cost information and strategy are positively associated with $\mathrm{ABC}$ adoption. Larger companies in terms of sales are more likely to adopt $\mathrm{ABC}$ than smaller companies. It is important to note that companies with sales of less than $\$ 50$ million were excluded from this study. As the importance of cost information increases, companies adopt $\mathrm{ABC}$ at higher rates indicating accurate costs from $\mathrm{ABC}$ are more desired. Companies with strategies dependent on accurate costing adopt $\mathrm{ABC}$ at higher rates. Three variables were found to be negatively associated with $\mathrm{ABC}$ adoption: cost structure, intensity of completion and industry sector. Cost structure is the most surprising finding as it was one of the primary motivators for the introduction of ABC. Similarly, as the intensity of competition increases companies adopt ABC less. This may indicate that companies are price-takers not price-makers in this scenario; which is consistent with the findings on strategy.

The findings only support the third hypothesis, $\mathrm{H}_{3}$ : Cost structure is a significant predictor of $\mathrm{ABC}$ adoption. Overall, there is a negative relationship between cost structure and ABC adoption. As companies become more dependent on capital investments for equipment and their cost structure shifts from direct labor to overhead, they are less likely to adopt ABC. The findings do not support hypotheses $\mathrm{H}_{1}$ (intensity of competition), $\mathrm{H}_{2}$ (organizational size), $\mathrm{H}_{4}$ (importance of cost information), $\mathrm{H}_{5}$ (strategy), and $\mathrm{H}_{6}$ (industry sector); thus suggesting other contextual factors may impact $\mathrm{ABC}$ adoption. One potential variable that has yet to be investigated is the implementation of a new computer or enterprise resource planning system (ERP). As companies implement new systems, they may be more likely to adopt $\mathrm{ABC}$ as part of the process redesign.

This study is a continuation of $\mathrm{ABC}$ adoption research that was initiated when researchers began to address why $\mathrm{ABC}$ is not more widely adopted (Al-Omiri and Al-Qura, 2012; Askarany et al., 2010; Charaf and Bescos, 2013; Nassar et al., 2013; Schoute, 2011). The intent of the study is to understand the relationship among contextual factors and $\mathrm{ABC}$ adoption for service and manufacturing companies or SBU's from the United States. While not surprising, given the results of other studies on ABC adoption, this study points to a need for qualitative MA research to determine not only why there is a lack of enthusiasm for $\mathrm{ABC}$ in the practitioner community, but also suggests a possible need for MA academicians to work cooperatively with MA practitioners to research, devise, and develop MA tools that can advance the profession. 
This study has several limitations that may suggest avenues for further research. This study is limited to a select group of large service and manufacturing companies and SBU's who could accrue the greatest benefit from $\mathrm{ABC}$ adoption. Excluding smaller companies may have artificially increased $\mathrm{ABC}$ adoption rates. Industry-specific research (e.g. auto industry) with specific industry contextual factors may advance this knowledge about $\mathrm{ABC}$ adoption. With only cost structure found to be a significant negative predictor of $\mathrm{ABC}$ adoption, other contextual factors should be evaluated for the impact on $\mathrm{ABC}$ adoption such as the cost of $\mathrm{ABC}$ adoption, financial and human resource limitations, sufficiency of extant costing systems in subsequent research, and the impact of ERP systems. It is expected companies with similar size in terms of sales and industry sector in the United States and other developed countries may experience similar ABC adoption rates. For smaller companies within the United States and other developed countries as well as undeveloped countries, it is unlikely these results are representative of their experience with $\mathrm{ABC}$ adoption.

\section{REFERENCES}

Abdel-Kader, M., \& Luther, R. (2006). Management accounting practices in the British food and drinks industry. British Food Journal, 108(5), 336-357.

Abdel-Kader, M., \& Luther, R. (2008). The impact of firm characteristics on management accounting practices: A UK-based empirical analysis. British Accounting Review, 40(1), 2-27.

Ahmadzadeh, T., Etemaldi, H., \& Pifeh, A. (2011). Exploration of factors influencing on choice of activity-based costing system in Iranian organizations. International Journal of Business Administration, 2(1), 61-70.

Al-Omiri, A., \& Al-Qura, U. (2012). The motives driving activity-based costing adoption: an empirical study of Saudi firms. The Journal of American Academy of Business, 17(2), 62-77.

Al-Omiri, M., \& Drury, C. (2007a, November/December). Organizational and behavioral factors influencing the adoption and success of ABC in the UK. Cost Management, 38-48.

Al-Omiri, M., \& Drury, C. (2007b). A survey of factors influencing the choice of product costing systems in UK organizations. Management Accounting Research, 18(4), 399-424.

Anderson, S. (1995, Fall). A framework for measuring cost management system changes: the case of activity-based cost at General Motors, 1986-1993. Journal of Management Accounting Research, $1-51$.

Anh, D., Nguyen, D., \& Mia, L. (2011). Western management accounting practices in Vietnamese enterprises adoption and perceived benefits. Pacific Accounting Review, 23(2), 142-164.

Argyris, C., \& Kaplan, R. S. (1994). Implementing new knowledge: the case of activity-based costing. Accounting Horizons, 8(3), 83-105.

Armitage, H., \& Nicholson, R. (1993). Activity-based costing: a survey over Canadian practice. Issue Paper No. 3, Society of Management Accountants of Canada.

Askarany, D., \& Yazdifar, H. (2012). An investigation into the mixed reported adoption rates for ABC: evidence from Australia, New Zealand and the UK. International Journal of Production Economics, 135, 430-439.

Askarany, D., Yazdifar, H., \& Askary, S. (2010). Supply chain management, activity-based costing and organizational factors. International Journal of Production Economics, 127(2), 238-248.

Baird, K., Harrison, G., \& Reeve, R. (2004). Adoption of activity management practices: a note on the extent of adoption and the influence of organizational and cultural factors. Management Accounting Research, 15, 383-399.

Baird, K., Harrison, G., \& Reeve, R. (2007). Success of activity management practices: the influence of organizational and cultural factors. Accounting \& Finance, 47(1), 47-67.

Booth, P., \& Giacobbe, F. (1999). Activity-based costing in Australian manufacturing firms the 'state of play'. Contemporary Perspectives in Management Accounting, Management Accounting Center for Excellence, Australia, Melbourne. 
Brierley, J. (2008). Toward an understanding of the sophistication of product costing systems. Journal of Management Accounting Research, 20, 61-78.

Brown, D., Booth, P., \& Giacobbe, F. (2004). Technological and organizational influence on adoption of activity-based costing in Australia. Accounting and Finance, 44(3), 329-356.

Cardos, I., Pete, Ş., \& Cardos, V. (2012). An overview on the adoption and implementation of activitybased costing in practice. Revista Romana de Economie, 35(2), 185-200.

Charaf, K., \& Bescos, P. (2013). The role of organizational and cultural factors in the adoption of activity-based costing: the case of Moroccan firms. Accounting and Management Information Systems, 12(1), 4-21.

Chenhall, R. (2006). Theorizing contingencies in management control systems. Research Handbooks of Management Accounting Research, 1(4), 163-205.

Chenhall, R., \& Langfield-Smith, K. (1998). Adoption and benefits of management accounting practices: An Australian study. Management Accounting Research, 9, 1-19.

Clarke, B., \& Mia, L. (1993). Activity-based costing systems: use and application in Australia, paper. European Accounting Association Conference, Maastricht.

Cooper, R. (1988a, Summer). The rise of activity-based costing- part one: what is an ABC system? Journal of Cost Management, 45-54.

Cooper, R. (1988b, Fall). The rise of activity-based costing- part two: when do I need an activity-based cost system? Journal of Cost Management, 41-48.

Cooper, R. (1989a, Winter). The rise of activity-based costing- part three: how many cost drivers do you need and how do you select them? Journal of Cost Management, 34-46.

Cooper, R. (1989b, Spring). The rise of activity-based costing- part four: what does an ABC system look like? Journal of Cost Management, 38-49.

Cooper, R. (1991). A structural approach to implementing ABC. Accountancy, 78-80

Cooper, R., \& Kaplan, R. (1988). Measure costs right: Make the right decisions. Harvard Business Review, 66(5), 96-103.

Drury, C., \& Tayles, M. (2000). Cost systems and profitability analysis in the UK companies: discussing survey findings. Proceedings of $23^{\text {rd }}$ Annual Congress of BAA, Munich.

Elhamma, A. (2012). The relationship between firm size, activity-based costing and performance: an application on Moroccan enterprises. Journal of Accounting-Business \& Management, 19(1), 90102.

Elhamma, A., \& Fei, Z. (2013). The relationship between activity-based costing, business strategy and performance in Moroccan enterprises. Accounting and Management Information Systems, 12(1), 22-38.

Ernst \& Young. (2003). The state of management accounting updates. Cost and Management Updates, 124.

Estrin, T., Kantor, J., \& Albers, D. (1994). Is ABC suitable for your company? Strategic Finance, 10(75), 40-45.

Gosselin, M. (1997). The effect of strategy and organizational structure on the adoption and implementation of activity-based costing. Accounting, Organizations and Society, 22(2), 105-122.

Grondskis, G., \& Sapkauskiene, A. (2011). Cost accounting information use for product mix design. Economics and Management, 16, 48-53.

Innes, J., \& Mitchell, F. (1995, July/August). ABC: a follow-up survey of CIMA members. Management Accounting (UK), 50-51.

Innes, J., Mitchell, F., \& Sinclair, D. (2000). Activity-based costing in the U.K.'s largest companies: a comparison of 1994 and 1999 survey results. Management Accounting Research, 11, 349-362.

Jankala, S., \& Silvola, H. (2012). Lagging effects of the use of activity-based costing on the financial performance of small firms. Journal of Small Business Management, 50(3), 498-523.

Johnson, H. T., \& Kaplan, R. S. (1987). Relevance Lost: The Rise and Fall of Management Accounting. Boston, MA: Harvard Business School Press. 
Kaplan, R., \& Cooper, R. (1998). Cost and effect: using integrated systems to drive profitability and performance. Boston: Harvard Business School Press.

Khandwalla, P. (1972). The effect of different types of competition on the use of management control systems. Journal of Accounting Research, 10(2), 275-285.

Krumwiede, K. (1998). The implementation stages of activity-based costing and the impact of contextual and organizational factors. Journal of Management Accounting Research, 10, 239-277.

McGowan, A., \& Klammer, T. (1997). Satisfaction with activity-based costing management implementation. Journal of Management Accounting Research, 9, 217-238.

Miles, R. E., \& Snow, C. C. (1978). Organizational Strategy, Structure, and Process. New York: McGraw-Hill.

Mouline, J. (2000). La PME familiale francaise et son orientatation strategique une etude exploratatoire.

Nassar, M., Al-Khadash, H., Sangster, A., \& Mah'd, O. (2013). Factors that catalyse, facilitate and motivate the decision to implement activity-based costing in Jordanian industrial companies. Journal of Applied Accounting Research, 14(1), 18-36

Pavlatos, O., \& Paggios, I. (2009). Activity-based costing in the hospitality industry: evidence from Greece. Journal of Hospitality and Tourism Research, 33(4), 511-527.

Rhaba'h, A. (2013). The influence of company characteristics factors to activity-based costing systems implementation, Journal of Education and Vocational Research, 4(2), 36-46.

Schoute, M. (2011). The relationship between product diversity, usage of advanced manufacturing technologies and activity-based costing adoption. The British Accounting Review, 43,120-134.

Sleihat, N., Al-Nimer, M., \& Almahamid, S. (2012). An exploratory study of the level of sophistication of management accounting practices in Jordan. International Business Research, 5(9), 217-234.

Snow, C. C., \& Hrebiniak, L. G. (1980). Strategy, distinctive competence, and organizational performance. Administrative Science Quarterly, 25(2), 317-336.

Stratton, W., Desroches, D., Lawson, R., \& Hatch, T. (2009). Activity-based costing: is it still relevant? Management Accounting Quarterly, 10(3), 31-40. 